\title{
AN ASSESSMENT OF THE FAILURE OF FLAME RETARDANT BASED COMPOSITE LAMINATES UNDER MECHANICAL LOADING
}

\author{
${ }^{*}$ Suoware, T. O., ${ }^{2}$ Edelugo, S. O., ${ }^{1}$ Amgbari, C. O. and ${ }^{2}$ Sorgbara, F. L.
}

\author{
${ }^{*}$ Department of Mechanical Engineering Technology, Federal Polytechnic, Ekowe, Bayelsa State \\ *Phone: +2347037201960*Email: Suoware.research@gmail.com \\ ${ }^{2}$ African Centre of Excellence, ACE-SPED, University of Nigeria, Nsukka \\ Phone: +2347037463298 Email: Sylvester.edelugo@unn.edu.ng
}

\begin{abstract}
Composite laminates have distinct interface comprising reinforcements from both synthetic or natural sources and polymers which make them favourable in the world of composites due to the intrinsic benefits they possess. Composite laminates from natural sources have shown to be highly susceptible to flame and have been improved by the addition of flame retardants (FR) during processing. The effect of the FR on the mechanical behaviour of these composite laminates is quite unclear and has not been given the in-depth attention. In this paper, the effect of FR of two set of composite laminates on mechanical failure was assessed. The two set of composite laminates comprising oil palm fibre composite (OPFC) and wood sawdust composite (WSC) were processed with polyester resin and six (6) FR using hand-lay compression moulding. The FRs were derived from aluminium tri-hydroxide (ATH), ammonium polyphosphate (APP), gum Arabic powder (GAP) and carbon black (CB) at 12\%, 15\% and 18\% loading ratios. Specimen cut from the composite laminates were tested for failure under tensile and flexural loading using the universal testing machine (UTM). The results obtained shows that the addition of 15\%APPGAP/CB in WSC and 12\%APP-GAP in WSC exhibited an outstanding performance in improving tensile and flexural strength of the composite laminates by $154 \%$ (from $9.67 \mathrm{MPa}$ to $24.56 \mathrm{MPa}$ ) and $103.4 \%$ (from $42.14 \mathrm{MPa}$ to $85.7 \mathrm{MPa}$ ) respectively compared to those without FR while the FR in OPFC did not show any significant improvements. It can be concluded that FR with particulate reinforcement could improve the mechanical behaviour of composite laminates as a suitable reinforcement.
\end{abstract}

Keywords: composite laminates, flame retardant, failure assessment, oil palm fibre, tensile properties, wood sawdust

LICENSE: This work by Open Journals Nigeria is licensed and published under the Creative Commons Attribution License 4.0 International License, which permits unrestricted use, distribution, and reproduction in any medium, provided this article is duly cited.

COPYRIGHT: The Author(s) completely retain the copyright of this published article.

OPEN ACCESS: The Author(s) approves that this article remains permanently online in the open access (OA) mode.

QA: This Article is published in line with "COPE (Committee on Publication Ethics) and PIE (Publication Integrity \& Ethics)". 


\section{INTRODUCTION}

Fibres or particulates embedded in polymer matrix which form a unified material structure with distinct interface are the best example of modern-day composite materials. Natural fibres (NF) such as jute, sisal, hemp, flax, kenaf, sugarcane, banana, oil palm, coir, wood and others are naturally grown. They consist of organic constituents which make up cellulose, hemicellulose and lignin, and are usually called lignocellulosic or cellulosic fibres. NF derives their strength and rigidity from cellulose, a semi crystalline polysaccharide in nature. Cellulose-based fibres obtained from plants are broadly used in polymer composites due to their abundance and renewability within a short time when compared to animal or mineral sources as stated by Majeed et al. (2013). Among the NF, the bast fibres extracted from the stems of plants have been accepted as the best candidates for reinforcements of polymer composites due to their good mechanical properties as reported by Nair et al. (2000).

The mechanical properties of various composite laminates derived from natural sources such as oil palm fibre composite (OPFC) and wood sawdust composite (WSC) have been reported. Ramlee et al. (2019) studied the tensile, physical and morphological properties of hybrid OPF and bagasse reinforced phenolic composite laminates. The results obtained with the universal testing machine shows the mechanical properties obtained stood at 5.56MPa and 661MPa respectively for tensile strength and modulus. Sawawi et al. (2020) showed that the mechanical properties for a chemically-treated oil palm empty fruit bunch reinforced with urea formaldehyde resin particle board type were of high improved quality. Nordin et al. (2020) also showed that the tensile properties obtained were reduced for heat treated oil palm fibre fruit bunch/high-density polyethylene composite. Kumar et al. (2019) studied the effect of wood sawdust plastic on the mechanical properties and found that increasing wood powder proportion results in higher young modulus and decreased stress rate. Jaya et al. (2018) showed the effect of wood sawdust loading on tensile and physical properties of unsaturated polyester composite and found that the wood sawdust can improve the mechanical properties effectively.

The applications of natural fibre reinforced polymer-based composites are restricted to areas were fire safety is not a key consideration. Current research is finding a way to make it suitable as a fire-resistant composite for automobile and building interior applications. Khalili et al. (2017a), Khalili et al. (2017b), Ren et al. (2015) have reported that the addition of FR additives can improve fire properties but the composite laminates could affect the tensile properties, flexural strength and impact strength of the composites. There is scarce literature on the effect on the mechanical properties of flame retardant OPF and wood sawdust reinforced polyester. This paper tends to find out the possibility of adding FR additives to composite laminates as well as retain its mechanical properties. Therefore, the main objective of this paper is to investigate the effect of FR on OPFC and WSC failure under mechanical loading. The knowledge will be useful in selecting flame retardant composite laminates with minimal or no effect of FR on their mechanical properties. 


\section{MATERIALS AND METHODS FIBRE/PARTICULATE PREPARATION}

Fibres and wood sawdust used for the composite laminates were first treated with $5 \% \mathrm{NaOH}$ to improve on their compatibility with the polyester resin. It was then washed with distilled water to remove excess $\mathrm{NaOH}$ and then sun dried for fibres whereas the wood sawdust were oven dried for $3 \mathrm{hrs}$ at $80^{\circ} \mathrm{C}$ to remove moisture content. The ready to use oil palm fibres and wood sawdust were then used as reinforcements to prepare the composite laminates. A detailed treatment process can be found in our previous published article by Suoware et al. (2019).

\section{PREPARATION OF COMPOSITE LAMINATES}

The oil palm fibre composite and wood sawdust composite were prepared using hand lay-up compression moulding technique. The composite laminates were processed with flame retardant comprising aluminium tri-hydroxide (ATH), ammonium polyphosphate (APP), Gum Arabic powder (GAP) and carbon black (CB) at different loading ratios. The FR which formed a pasty solution with the resin where poured into a mould containing the fibres as shown in our previous article by Suoware et al. (2019) whereas the wood sawdust formed part of the party solution. The required fibre and particulate as well as the polyester resin were obtained through mass fraction model found in Suoware et al. (2019) published article.

\section{CHARACTERIZATION}

The composite laminates were subjected to a static tensile and flexural test according to ASTM D 638 and ASTM D 790 standards respectively using a universal testing machine (Hounsfield model No. 8898) as shown in Figure 1a. To obtain tensile properties the specimens as shown in Figure $1 \mathrm{~b}$ were held horizontally and the ends of the specimens were position in the mechanical grips. The grips were tightened sufficiently to avoid slippage. The speed to pull out the specimens was $2 \mathrm{~mm} / \mathrm{min}$ at a temperature of $22^{\circ} \mathrm{C}$ and humidity of $50 \%$ in all cases. The load cell rating is a $5000 \mathrm{~N}$ and the distance between the holders fixed at $40 \mathrm{~mm}$. Stress-strain curves were plotted from the force-extension data obtained on a special graph sheet during the tests and the required tensile properties were determined; tensile strength and tensile modulus obtained by calculations using Equations: 1 and 2. For flexural test the specimens were placed vertically on a support span and the load is applied to the centre by the loading nose, producing three points bending at a specified rate. The flexural strength characteristic was studied and obtained by calculation using Equation 3. The test was repeated three times and an average value recorded in each test.

$$
\begin{aligned}
& \sigma_{U}=\frac{F_{\max }}{h w}[\mathrm{MPa}] \\
& E=\frac{\sigma}{\varepsilon}=\frac{F / h w}{\Delta L / L_{0}}[\mathrm{GPa}] \\
& F_{S}=\frac{3 F L}{2 b w^{2}}[\mathrm{MPa}]
\end{aligned}
$$

where, 
$\sigma_{U}=$ Ultimate tensile strength (MPa), $F_{\text {max }}$ is the maximum tensile load $(\mathrm{N}), F$ is the tensile Load $(\mathrm{N}), \Delta L$ is the change in length (mm), $L_{0}$ is the original Length of the specimen $(\mathrm{mm}), w$ is the width of the specimen $(\mathrm{mm})$ and $h$ is the thickness (mm) and $L=$ Distance between the two outer supports (mm).

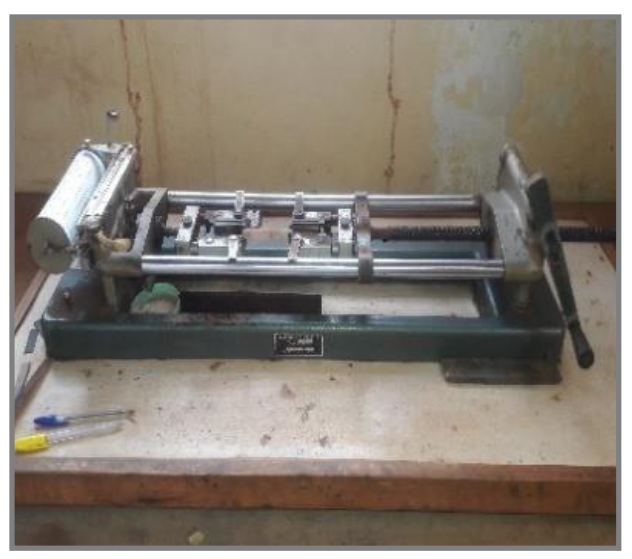

(a)

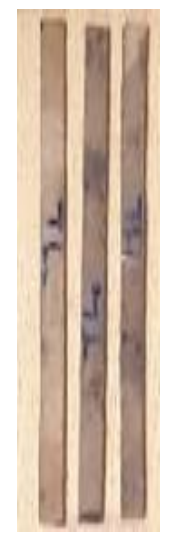

(b)

Figure 1: (a) Universal testing machine used for the tensile and flexural testing (b) Composite laminate test specimen

\section{RESULTS}

The effects of the flame retardant (FR) loading on the mechanical properties of the studied oil palm fibre composite and wood sawdust composite laminates were compared to the reference material (polyester resin) and with those without FR through three modes; tensile strength, tensile modulus and flexural strength. The standard error of the mechanical properties is shown in the graphs i.e. Figures 2, 3, 4 and 5. The error bars shown on the graphs indicate the level of data scatter from repeat testing of specimens subjected to the same testing conditions. The large error bar shown in Figure $2 \mathrm{~b}$ and $3 \mathrm{~b}$ could be attributed to a number of uncontrollable factors. These factors include but not limited to uncompensated system deflections resulting from measurement of stain-gauge based load cell, by their nature, deflect slightly as load is applied causing about $30 \%$ error measurement with potential large effect on force measurement. Wrong load cell capacity produces large error relative to the magnitude of the force being measured. 


\section{TENSILE PROPERTIES}

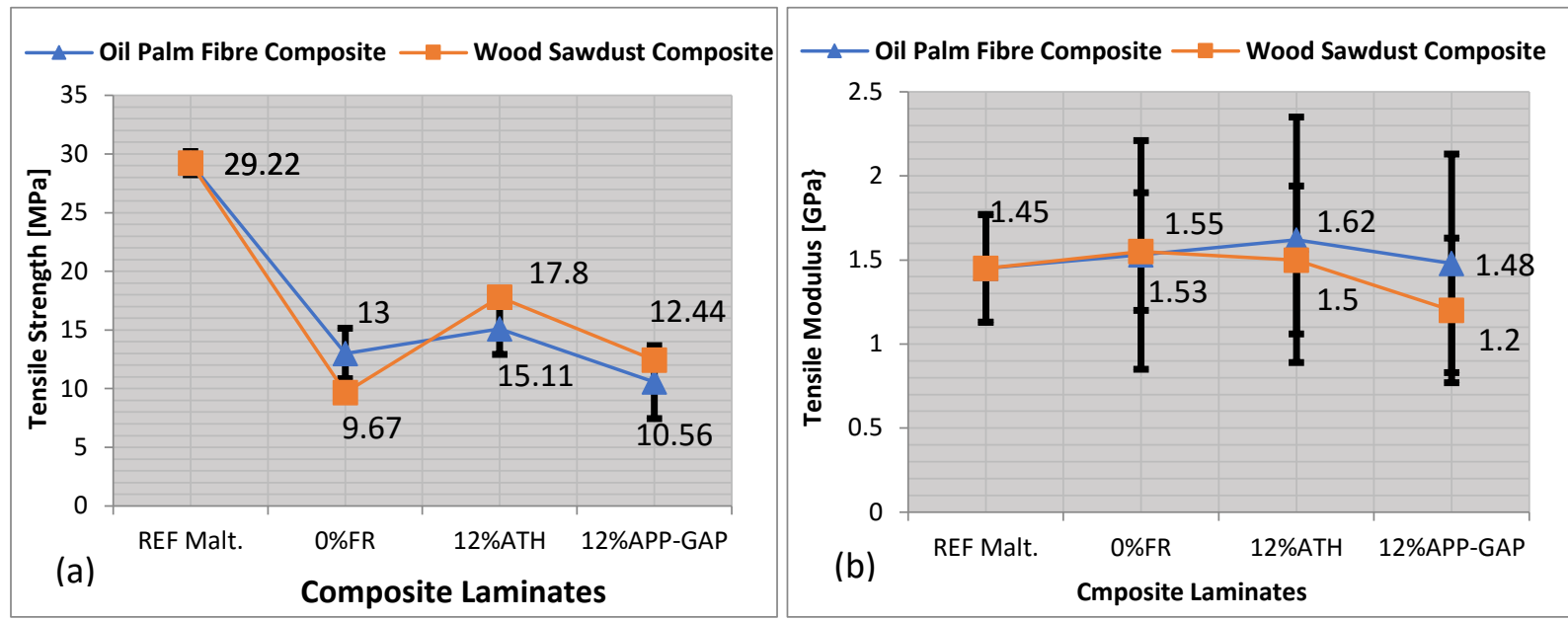

Figure 2: Composite laminates at 12\% FR loading (a) Tensile strength (b) Tensile modulus
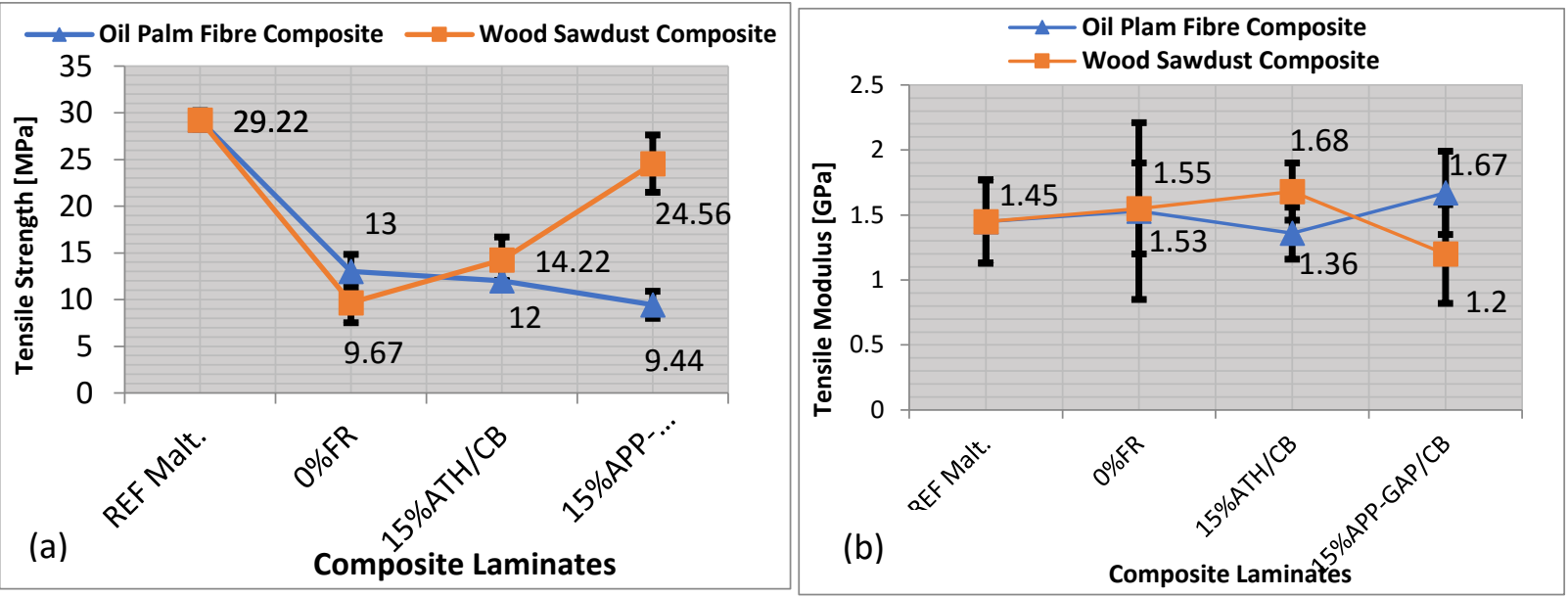

Figure 3: Composite laminates at 15\% FR loading (a) Tensile strength (b) Tensile modulus
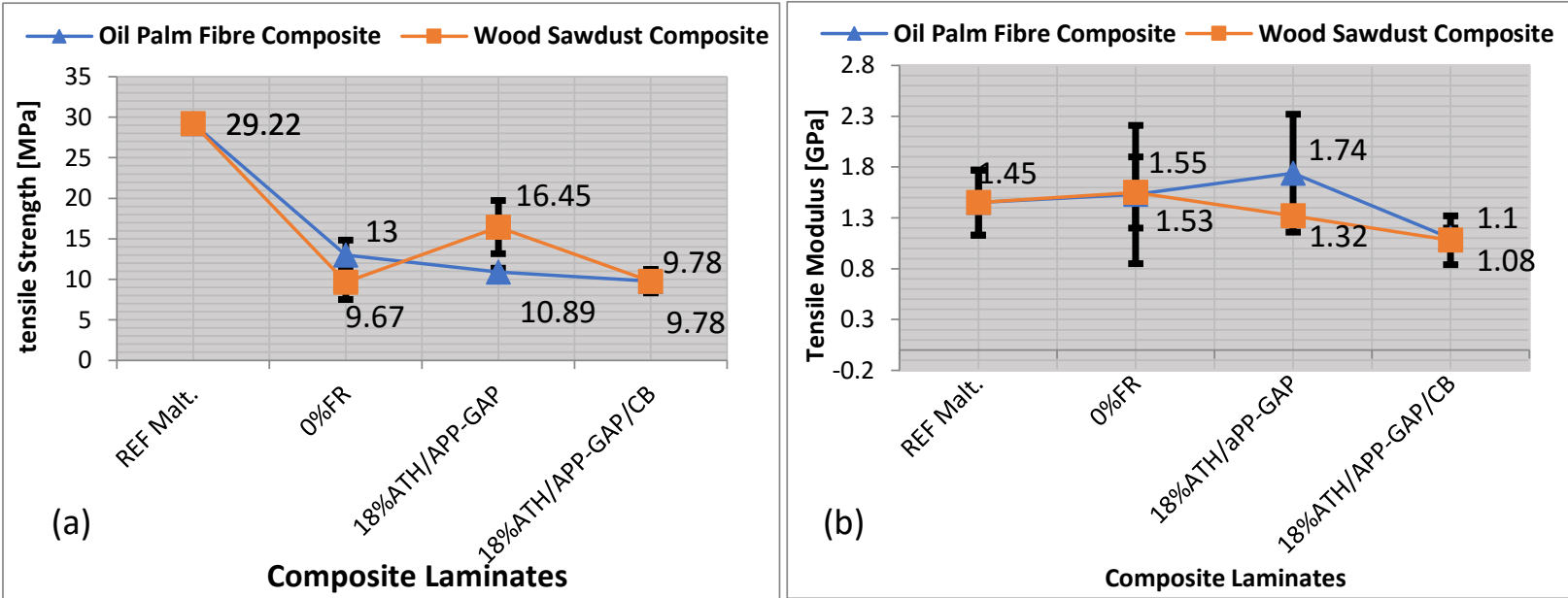

Figure 4: Composite laminates at 18\% FR loading (a) Tensile strength (b) Tensile modulus 


\section{FLEXURAL STRENGTH}

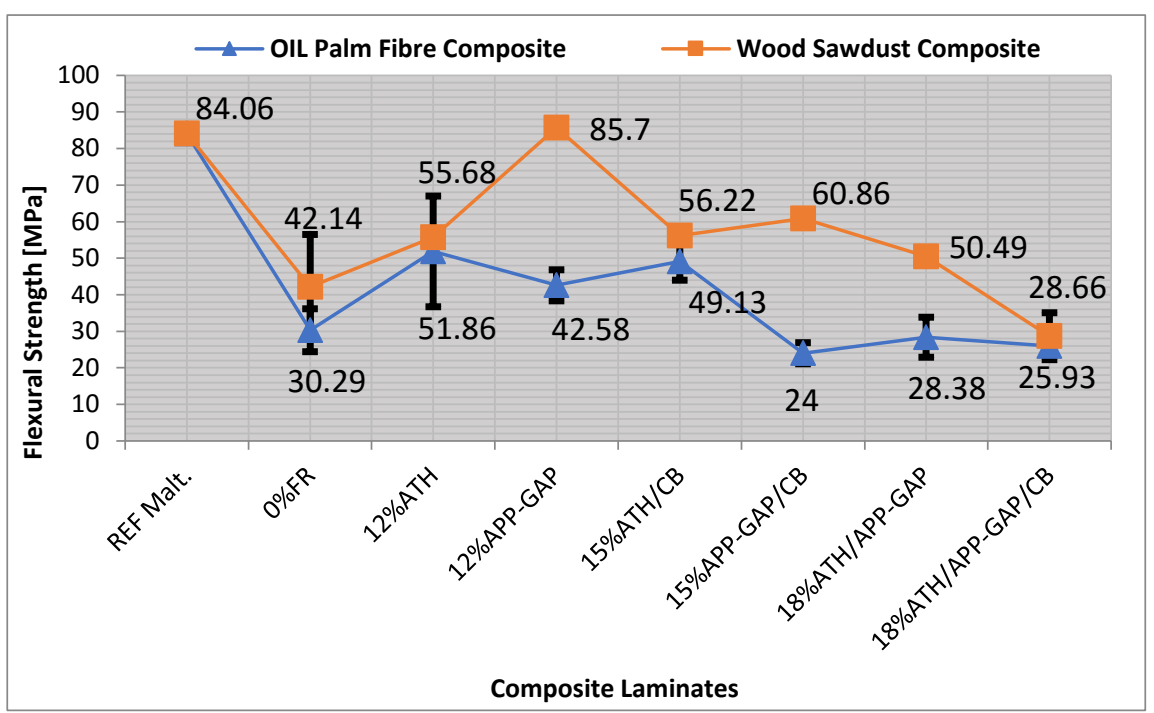

Figure 5: Flexural strength for the composite laminates at various FR loading

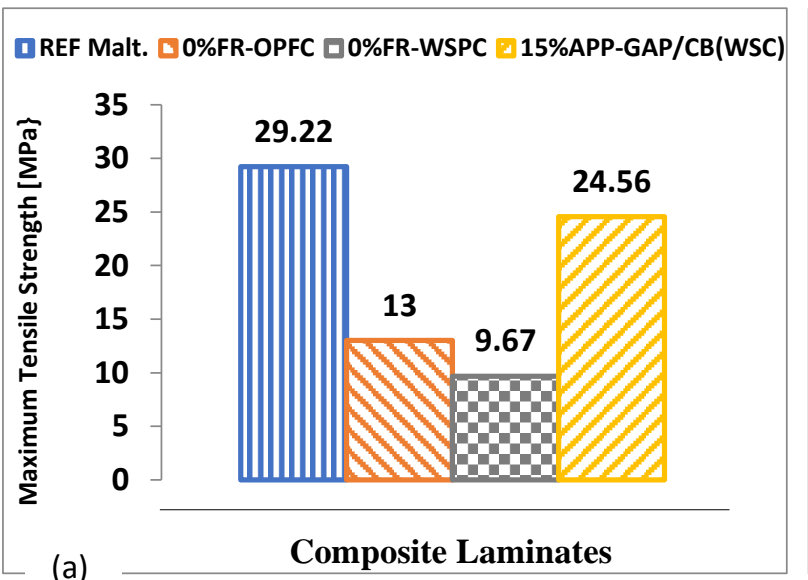

(a)

Figure 6: Comparison of the maximum composite laminate (a) tensile strength (b) Flexural strength with the reference material and those without FR

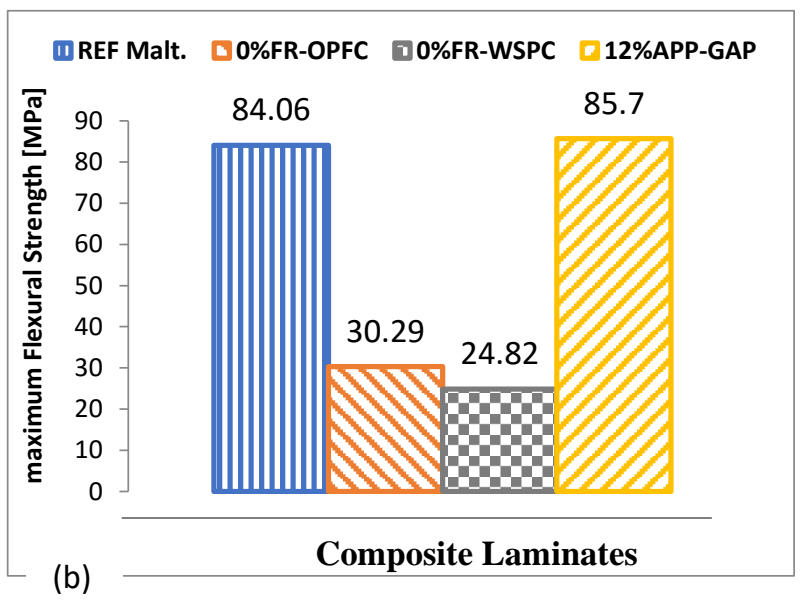

(b) $\frac{\text { Composite Laminates }}{\text { (a) tensile strength (b) Flexural strength with the }}$

\section{DISCUSSIONS}

\section{TENSILE STRENGTH}

Figure 2 shows the graph of the composite laminates response to tensile loading at $12 \%$ FR loading ratio. In Figure $2 \mathrm{a}$ it shows that the addition of OPFC and WSC reduced the tensile strength (TS) of the reference material (polyester resin) by $55.5 \%$ and $66.9 \%$ respectively. This is expected as reported by Nordin et al. (2020) and Choh et al. (2016). However, among the FR composite laminates the 12\% ATH in WSC and OPFC increases the TS by $84 \%$ and $16.2 \%$ respectively compared with those without FR. In Figure $2 b$ the tensile modulus (TM) shows that the addition of OPFC and WSC slightly increase in TM as well as for the 12\%ATH and 12\%APP-GAP composite laminates. The least TM 
value was observed for $12 \% \mathrm{APP}-\mathrm{GAP}$ in WSC when compared to the other composite laminates. The decrease in TS observed for the other FR loading is expected as similar trends were also reported for OPFC as seen in the work of Khalili et al. (2017), Redwan et al (2015) and Norzali et al. (2011). In Figure 3a the studied FR composite laminates show that the 15\%ATH/CB and 15\%APP-GAP/CB in WSC increases TS respectively by $47.1 \%$ and $154 \%$ compared to WSC without FR but decreased with increase in FR for OPFC.

On the other hand, the 15\%ATH/CB in WSC followed by the 15\%APP-GAP/CB in OPFC increases the TM slightly better compared to those without FR by $8.4 \% \%$ and $9.2 \%$ respectively. The FR probably acted as reinforcement to enhance the capability of transferring stresses. The least TS recorded for 15\%APP-GAP/CB in OPFC could be similar to the in-TS decrease found by Choh et al. (2016) with low-density polyethylene/OPEFB and CB, indicating a poor performance of CB on the TS. In Figure 4a in comparing the FR loading with those without FR it was observed that the 18\%ATH/APP-GAP in OPFC decreased with increase in FR while WSC enhanced in TS better by $26.5 \%$ and $12.6 \%$ respectively.

On the other hand, the 18\%ATH/APP-GAP/CB in OPFC and WSC recorded the least TS values indicating that the presence of $\mathrm{CB}$ in the composite laminates at higher FR exhibited a poor performance in tensile properties. The reason for this behaviour could be attributed to poor compatibility between the CB and PR at high FR loadings. The TM in Figure $4 \mathrm{~b}$ shows that the 18\%ATH/APP-GAP in OPFC exhibited an outstanding rigid composite laminate as TM increases by $13.7 \%$ compared to those without FR. The enhanced TM observed is an indication that the FR loading have significant effect on the interfacial bonding with the resin which restricted the movement of the polyester molecules.

\section{FLEXURAL STRENGTH}

Figure 5 shows the flexural strength (FS) of the composite laminates at 12-18\% FR loading ratio. From the graph it reveals that the $12 \%-18 \%$ FR loading in WSC were higher than those of OPFC. The reason could be that the FR acted as reinforcement with wood sawdust to improve stress transfers. The 12\%APP-GAP in WSC exhibited outstanding FS by $103.4 \%$ compared to the WSC without FR. It can be seen from the outcome of the studied composite laminates that the FR loading maintained a significant increase in FS for the composite laminates except for higher FR loadings. The reason for the decrease could be low wettability of the combined FR formulation at high concentrations and/or due to agglomerate formation of the composites. The enhanced FS for the various FR loading ratio studied falls within the range of $50 \mathrm{MPa}$ to $85 \mathrm{MPa}$. This value falls within the range of FS reported by Chindaprasirt et al. (2015) and Nabinejad et al. (2017) on wood reinforced polymer composites.

\section{COMPARISON OF MAXIMUM MECHANICAL PROPERTIES}

In Figure 6, a comparison of the maximum tensile strength and flexural strength with those without FR and the reference material was assessed. This figure shows that the 15\%APP-GAP/CB in WSC enhanced better the studied composite laminates as it reached maximum TS of 24MPa from 9.67MPa. This implies that the particulates of the wood sawdust and the FR loading were homogenously dispersed in the resin giving a better interfacial adhesion between the constituents as reported by Ashori (2008). The presence of CB in the FR formulations probably inhibited 
the crosslinking among the host molecules and correspondingly increased its stiffness as stated by Redwan et al. (2015) and Nabinejad et al. (2017). Similar trend was reported by Ren et al. (2015) were it was observed that WFIFR with zinc borate (ZB), montmorillonite (MMT) and stannic oxide $\left(\mathrm{SnO}_{2}\right)$ synergist exhibited a significant increase in TS. In Figure $6 \mathrm{~b}$ the $12 \% \mathrm{APP}-\mathrm{GAP}$ in WSC recorded a significant increase from 24.82MPa to $85.7 \mathrm{MPa}$. The increase in FS for 12\%APP-GAP in WSC laminate could be attributed to effective interfacial bonding between APPGAP and WSP/PR. The GAP played a significant role as it took longer period during curing leading to enhanced mechanical properties. This increase in FS agrees with the findings of Bai et al. (2014). and Bledzki and Gassan (1999) also reported that increase in FS of wood reinforced composites could be related to higher cellulose and lignin content present in woods.

\section{CONCLUSIONS}

In this study, an assessment of the failure of flame retardant based composite laminates under tensile and flexural loading was evaluated and the underlisted were conclusively derived from the study:

i. the addition of oil palm fibre and wood sawdust to polyester resin reduced tensile and flexural strength of the composite laminates.

ii. the FR in OPFC caused a decrease in tensile strength with increase in FR while FR in WSC caused increase in tensile strength with increase in FR.

iii. the addition of $12 \%$ ATH in WSC and 12\%APP-GA in OPFC laminates exhibited better tensile properties compared with those without FR.

iv. the flame-retardant loading ratios in WSC were higher than those of OPFC laminates in terms of their flexural behaviour.

v. the addition of $15 \%$ APP-GAP/CB and 12\%APP-GAP in WSC exhibited an outstanding performance in improving respectively the tensile and flexural strength of the composite laminates.

\section{ACKNOWLEDGEMENT}

The authors hereby appreciate and acknowledge the African Centre of Excellence, ACE-SPED, University of Nigeria, Nsukka for their support and the management of Federal Polytechnic, Ekowe for its travel approvals. 


\section{REFERENCES}

Ashori, A (2008). Wood-Plastics Composites as Promising Green-Composites for Automotive Industries, BioResources Technology, 99: 4661-4667

Bai, G., Guo, C., and Li, L., (2014) "Synergistic Effective of Intumescent Flame Retardant and Expandable Graphite on Mechanical and Flame-Retardant Properties of Wood Flour-Polypropylene Composites" Construction and Building Materials 50, p 148-153.

Bledzki, A. K. and Gassan J. (1999). Composites Reinforced with Cellulose Based Fibres. Progress in Polymer Science 24:221-227

Choh, J. L., Ching, Y.C., Gan, S. N., Rozali, S. and Julia, S. (2016). Effect of Oil Palm Empty Fruit Bunch Fibre on Electrical and Mechanical Properties Conductive Filler Reinforced Polymer Composites. BioResources 11(1): 913-928

Chindaprasirt, P., Hizioglu, S., Waisurasingha, C. and Kasemiri, P. (2015). Properties of Wood Flour/Expanded Polystyrene Waste Composites Modified with Diammonium Phosphate Flame Retardant. Polymer Composites 11: 604-612.

Jaya, H; Noriman, N.Z; Abdulkadir, H.K; Dahham, O.S; Muhammad, N; Latip, N.A and Aini, A.K (2018). The Effect of Wood Sawdust Loading on Tensile and Physical properties of Up/pF/Wsd Composite. International Conference on Materials Engineering and Science, 454012193 doi:10.1088/1757-899X/454/1/012193

Kumar, S., Vedrtnam, A., Pawar, S. J. (2019). Effect of Wood Sawdust Type on Mechanical Properties, Wear Behaviour, Biodegradability and Resistance to Natural Weathering of Wood-Plastic Composite. Frontiers of Structural and Civil Engineering 13: 1446-1462

Khalili, P., Tshai, K.Y., Hui, D. and Kong, I. (2017a). Synergistic of Ammonium Polyphosphate and Alumina Trihydrate as Fire Retardants for Natural Fiber Reinforced Epoxy Composite Composites 114:101 -110

Khalili, P., Tshai, K.Y., Kong, I., (2017b) "Natural Fibre Reinforced Expandable Graphite Filled Composites: Evaluation of the Flame Retardancy, Thermal and Mechanical Performances Composites 100: 194 -205

Bai, G., Guo, C., and Li, L., (2017) "Natural Fibre Reinforced Expandable Graphite Filled Composites: Evaluation of the Flame Retardancy, Thermal and Mechanical Performances Composites 100: 194 -205

Majeed, K., Jawaid, M., Hassan, A., Abu Bakar, A., Abdul Khalil, H.P.S., Salami, A.A. and Inuwa, I. (2013). Potential Materials for Food Packaging form Nano/Natural Fibres Filled Hybrid Composites Materials. Description 46: $391-410$

Norzali, N. A. R. Badri, K. H. and Nuawi, M. Z. (2011). Loading Effect of Aluminum Hydroxide onto the Mechanical, Thermal Conductivity, Acoustical and Burning Properties of the Palm-based Polyurethane Composites Sains Malaysiana 40(7), pp 737-742

Nabinejad, O., Sujan, D., Rahman, M.E. and Davies, I. J. (2017). Effect of Filler Load on the Curing Behaviour and Mechanical and Thermal Performance of Wood Flour Filled Thermoset Composites. Journal of Cleaner Production 164:1145-1156 
Nordin, et al. (2020). Conditioning Effect on the Mechanical and thermal properties of Heat-treated oil Palm Fibre Fruit Bunch/High-density polyethylene Composite. Journal of High-performance Polymer 32(2):158-167 https://doi.org/10.1177/0954008319893418

Nair, K.C.M., Kumar, R.P., Thomas, S., Schit, S. C. and Ramamurthy, K. (2000). Rheological Behavior of Short Sisal Fiber-Reinforced Polystyrene Composites, Composites 31:1231-40

Ramlee, N. A., Jawaid, M., Zainudin, E. S. and Yamanji, S. A. K. (2019). Tensile, Physical and Morphological Properties of Oil palm Fibre/Sugarcane Bagasse Reinforced Phenolic Hybrid Composites. Journal of Material Research \& Technology, 8(4); 3466-3474

Redwan, A. M., Badri, K. H. and Tarawneh, M. A. (2015). The effect of Aluminium Hydroxide on the Mechanical Properties of Fire Resistivity of Palm-Based Fiberborad prepared by Pre-Polymerization Method Advanced Materials Research 1087:287-292

Ren Y., Wang, Y, Wang L. and Liu, T (2015). Evaluation of Intumescent Fire Retardant and Synergistic Agents for use in Wood Flour/Recycled Polypropylene Composites, Construction and Building materials, 76:273-278

Suoware, T. O., Edelugo, O. S. and Ezema, I. C. (2019). Effects of Flame Retardant on Flame Propagation and Flammability Properties of Oil Palm Fibre Reinforced Polyester Composite. Fire and Materials, 43:1-10. https://doi.org/10.1002/fam.2740

Suoware, T. O., Edelugo, O. S. and Ezema, I. C. (2019). Impact of Hybrid flame Retardant on the Flammability and Thermomechanical Properties of Wood Sawdust Polyester Composite Panel" Fire and Materials, 43 (3):335-343

Sawawi, M., Mohammad, N. H., Sahari, S. K., Junaidi, E. and Bazali, N. T. (2020). Effects of Chemical Treatment on Mechanical Properties of Oil Palm Empty Fruit Bunch (EFB) with Urea Formaldehyde (UF) Resin Particleboard Type International Journal of Recent Technology and Engineering, 8(5):1330-1334. 